\title{
EFFICIENCY ANALYSIS OF SPUR GEARS WITH A SHIFTING PROFILE
}

\author{
A. Diez-Ibarbia • A. Fernandez del Rincon • M. Iglesias • A. de-Juan • \\ P. Garcia - F. Viadero
}

Received: date / Accepted: date

\begin{abstract}
A model for the assessment of the energy efficiency of spur gears is presented in this study, which considers a shifting profile under different operating conditions (40 - $600 \mathrm{Nm}$ and 1500 - $6000 \mathrm{rpm}$ ). Three factors affect the power losses resulting from friction forces in a lubricated spur gear pair, namely, the friction coefficient, sliding velocity and load sharing ratio. Friction forces were implemented using a Coulomb's model with a constant friction coefficient which is the wellknown Niemann formulation. Three different scenarios were developed to assess the effect of the shifting profile on the efficiency under different operating conditions. The first kept the exterior radii constant, the second maintained the theoretical contact ratio whilst in the third the exterior radii is defined by the shifting coefficient. The numerical results were compared with a traditional approach to assess the results.
\end{abstract}

Keywords Efficiency · power losses · frictional effect · load sharing $\cdot$ shifting profile

\section{List of Terms}

CFC Constant Friction Coefficient

$E$ Young's modulus

$F C$ Friction Coefficient

$F E$ Finite Element

IPL Instantaneous Power Losses

$L C M$ Load Contact Model

A. Fernandez del Rincon

Department of Structural and Mechanical Engineering . ET-

SIIT University of Cantabria

Avda. de los Castreos s/n. 39005 Santander. Spain

Tel.: +34-942200936

Fax.: +34-942201853

E-mail: fernandra@unican.es

\section{$L S$ Load Sharing}

$L S R$ Load Sharing Ratio $\left(F_{N} / F_{N \max }\right)$

$O C$ Operating Conditions

$S V$ factor Sliding Velocity factor $\left(V_{s} / V\right)$

$T_{G}$ Resistive torque applied on the gear

$V$ Pitch line velocity

$V F C$ Variable Friction Coefficient

$\beta_{b}$ Helix angle at base cylinder

$\mu_{m}$ Mean Friction Coefficient

$\rho_{O_{G}}$ Resistive torque applied on the gear

$v$ Poisson's coefficient

$b$ Gear Width

$d$ Mineral constant

$m$ Modulus

$u$ Gear Ratio

$u_{\text {loc }}$ Local deflections

$x_{1}$ Shift coefficient of the pinion

$x_{2}$ Shift coefficient of the driven gear

$F_{N \max }$ Maximum Contact Force

$F_{\text {tmax }}$ Maximum Tangentical Contact Force

$H_{\text {vinst }}$ Instantaneous Power Loss Factor

$H_{v}$ Power Loss Factor

$P_{\text {in }}$ Input Power

$P_{\text {loss }}$ Power Losses

$P_{\text {out }}$ Output Power

$R_{1 \text { ext }}$ Exterior Radius of the pinion

$R_{2 e x t}$ Exterior Radius of the driven gear

$R_{a}$ Mean Roughness

$V_{\Sigma C}$ Sum velocity

$V_{s}$ Sliding Velocity

$X_{L}$ Lubricant factor

$\eta_{\text {oil }}$ Dynamic Viscosity

$\rho_{c}$ Equivalent Curvature Radius

$\theta_{A}$ Starting of the contact angle

$\theta_{E}$ Ending of the contact angle

$\theta_{N}$ Angular pitch $(2 \pi / z)$ 
$\varepsilon_{1}$ Tip Contact Ratio of the pinion

$\varepsilon_{2}$ Tip Contact Ratio of the driven gear

$\varepsilon_{\alpha}$ Contact Ratio

$\varphi$ Pressure angle

$d d_{h t a}$ Dedendum of the cutter

$z_{1}$ Teeth number of the pinion

\section{Introduction}

An incremental improvement in the requirements in terms of Operating Conditions (OC) and efficiency for gear transmissions is foreseen in the near future $[13,17]$. A greater transmitted torque from the pinion to the driven gear is needed with an increase in spin speed. Furthermore, an improvement in the energy efficiency is required as a consequence of stricter environmental regulations and the need to save energy and therefore money.

Efficiency is a major aspect in gear transmissions $[8,10,11,20,21]$. Power losses can be typically classified by their load dependency because only gear elements are taken into account (roller bearing were not taken into account). This classification considers sliding and rolling friction forces between gear teeth as loaddependent losses, and windage and churning losses as the non load-dependent losses. Although in this study the maximum speed is $6000 \mathrm{rpm}$, only the load-dependent losses were taken into account, being considered neither windage nor churning losses. Specifically, as the rolling friction contribution can be ignored in the study conditions for the efficiency calculation [1], the sliding friction effects, hereinafter referred as friction forces, were revealed as the main source of a reduction in efficiency in this study.

The main goal of this study is to present and determine the influence of shifting profile effects on the energy efficiency of this mechanical system. Since the introduction of shifting has a major impact on the Load Sharing $(L S)$ distribution, and the $L S$ greatly affects the efficiency of the system, the study will begin with a detailed assessment of the $L S$ determination. In this regard, a broad variety of $L S$ formulations and shapes could be adopted, with different degrees of accuracy. Two different approaches will be described and compared in order to provide insight on the importance of the use of a correct $L S$ for efficiency calculation purposes. The first one is a classical approach which can be found in the literature [6]. The second one is based on the Load Contact Model $(L C M)$ previously developed by the authors [3-5].

To assess the effect of the shifting profile on the efficiency, three different scenarios were designed, namely, (i) fixed exterior radii, (ii) fixed theoretical contact ratio and (iii) exterior radii dependent on the shift coefficient. Thus, the influence of each parameter involved in the efficiency could be independently assessed.

In previous studies [3-5], an advanced model of spur gears was presented by the authors. This model calculated the contact forces and deformation using a combination of global and local deformation formulation. The former was obtained using a Finite Element $(F E)$ model and the latter using a formula derived from the Hertzian contact. Importantly, this model took into account the deflection of the teeth which meant that when a pair of gear teeth was in contact, the resulting deflection had an impact on the rest of the system. This effect gave a more realistic approach to modeling the contact which had an influence on efficiency.

The $L C M$ features were extended to include the analysis of non-standard gears because they are widely used in real transmission applications [9]. The shifting profile has an impact on the $L S$ and therefore affects the efficiency value. Hence, determining this impact will help to comprehend the difference between efficiency values for several shift coefficient cases. In this study, the shift coefficients of both the pinion and the driven gears were constrained to be equal in absolute value but with opposite signs, fulfilling $x_{1}+x_{2}=0$.

Section 2 provides the background to the calculation of efficiency depending on the chosen approach. Furthermore, the friction coefficient formulation used throughout this study is presented in this section, because it is a necessary parameter in the efficiency calculation. In Section 3 the results of the different scenarios developed are shown and in Section 4 the main conclusions are highlighted.

\section{Efficiency calculation}

The mechanical efficiency is defined as the relationship between energy output and energy input for a given period of time.

$\eta=\frac{P_{\text {out }}}{P_{\text {in }}}=\frac{P_{\text {in }}-P_{\text {loss }}}{P_{\text {in }}}$

where the output power $\left(P_{\text {out }}\right)$ equals the input power $\left(P_{\text {in }}\right)$ minus the power loss during contact $\left(P_{\text {loss }}\right)$. For the efficiency calculation, only power losses resulting from frictional effects are taken into account. Thus, the instantaneous power losses $\left(P_{\text {loss,inst }}\right)$ can be defined as:

$$
P_{\text {loss }, \text { inst }}=F_{R}(\theta) V_{s}(\theta)=\mu(\theta) F_{N}(\theta) V_{s}(\theta)
$$


where $F_{R}(\theta)$ is the friction force, $\mu(\theta)$ is the friction coefficient, $F_{N}(\theta)$ is the normal load and $V_{s}(\theta)$ is the sliding velocity at the specific position $\theta$.

Defining the power losses from the start point of the tooth under consideration (correspond to $\theta_{A}$ ) to its end point (correspond to $\theta_{E}$ ) as:

$$
\begin{aligned}
P_{\text {loss }} & =\int_{\theta_{A}}^{\theta_{E}} P_{\text {loss }, \text { inst }} d \theta \\
& =\frac{F_{\text {tmax }}}{\cos (\varphi)} \frac{V}{\theta_{N}} \int_{\theta_{A}}^{\theta_{E}} \frac{\mu(\theta) F_{N}(\theta) V_{s}(\theta)}{F_{N \max } V} d \theta
\end{aligned}
$$

where $F_{N \max }$ is the maximum contact force, $V$ the pitch line velocity along the mesh cycle, $\varphi$ the pressure angle, $F_{\text {tmax }}$ the maximum tangential force and $\theta_{N}$ the angular pitch.

To make an assessment of the value of the efficiency obtained, a non-dimensional parameter $\left(H_{\text {vinst }}\right)$ is defined by the factors inside the integral to clearly identify the impact of each coefficient that contributes to power losses.

$H_{\text {vinst }}=\frac{\mu(\theta) F_{N}(\theta) V_{s}(\theta)}{F_{N \max } V}$

Merging Equations 3 and 4, the power losses are defined as:

$P_{\text {loss }}=\frac{F_{\text {tmax }}}{\cos (\varphi)} \frac{V}{\theta_{N}} \int_{\theta_{A}}^{\theta_{E}} H_{v i n s t} d \theta$

As can be seen in Equation 4, three factors define the calculation of the power losses and therefore the efficiency [6]. These factors are the sliding velocity factor ( $S V$ factor), defined as $V_{s}(\theta) / V$, the friction coefficient $\mu(\theta)$ and the Load Sharing Ratio $(L S R)$ defined as the ratio between the instantaneous normal force $F_{N}(\theta)$ and the maximum normal force along the mesh cycle $F_{N \max }\left(L S R=F_{N}(\theta) / F_{N \max }\right)$. Where $F_{N \max }=$ $T_{G} / \rho_{o_{G}}$, being $T_{G}$ and $\rho_{o_{G}}$ the resistive torque applied to the gear and the base radius of the gear respectively.

The first, $S V$ factor, is calculated kinematically, thus, it is imposed by the movement. For $\mu(\theta)$, a wide range of formulations empirically calculated has been found in the literature $[2,20,21]$, concluding that the friction coefficient can be considered as (i) the variable friction coefficient $(V F C)$ or (ii) the constant friction coefficient $(C F C)$. In this study, the friction coefficient is obtained using the so called Niemann's formulation $[2,6,12,14]$ which is a constant friction coefficient along the contact (Equation 6).

$\mu_{m}=C F C=0.048\left(\frac{\frac{F_{N \max }}{b}}{V_{\sum C} \rho_{c}}\right)^{0.2} \eta_{o i l}^{-0.05} R_{a}^{0.25} X_{L}$ where $\rho_{c}$ the equivalent curvature radius in the pitch point, $b$ the gear width, $\eta_{\text {oil }}$ the oil dynamic viscosity, $R_{a}$ the roughness, and parameters $V_{\Sigma C}$ and $X_{L}$ are defined as:

$V_{\Sigma C}=2 V_{t} \sin (\varphi)$ and $X_{L}=\frac{1}{\left(\frac{F_{N \max }}{b}\right)^{d}}$

In this study, 75W90 mineral oil was used as the lubricant $(d=0.0651[11])$ and had a dynamic viscosity of $10.6 \mathrm{mPas}$ at a working temperature of $100{ }^{\circ} \mathrm{C}$. Moreover, the roughness considered is $0.8 \mu \mathrm{m}$.

As stated in the introduction, with regard to the $L S$, a broad variety of formulations and shapes could be used $[5,6,16]$. To assess the importance of using a correct $L S$ for efficiency calculation purposes, two different formulations will be used. The first one is a simplified analytical $L S$ formulation broadly used in the literature taken from ISO/TC-60 standard [7] (called uniform $L S$ ) and the second one is a numerical $L S$ formulation based on the $L C M$ previously developed by the authors [3-5].

To analyse the influence of using different $L S$ formulations, two efficiency approaches have been used and presented below, the well-known Höhn et al. approach and the proposed by the authors approach. The former uses the analytical $L S$ taken from ISO/TC-60 standard [7] and a constant $F C$. The latter presents the advantage of the formulation flexibility since any friction coefficient and $L S$ formulation can be used to obtain the efficiency. In order to assess the influence of $L S$ in the efficiency calculation, both approaches have considered a constant $F C$. Hence, Höhn et al. approach considers a uniform $L S$ whereas the proposed approach uses a more realistic $L S$ formulation (see Figure 1, $L C M$ with friction and ISO/TC-60 curves).

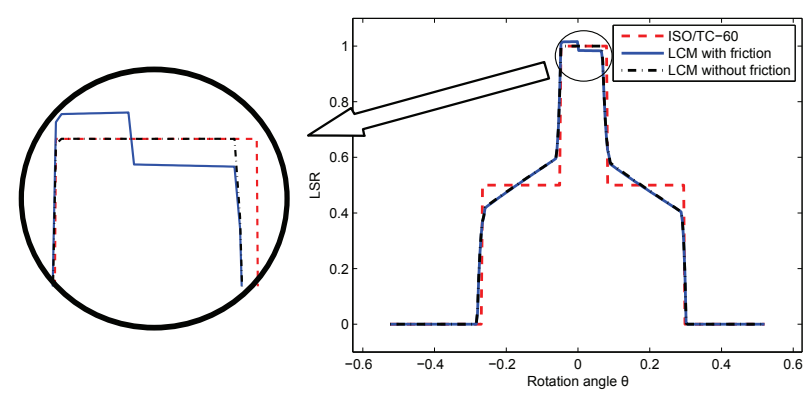

Fig. 1: Load Sharing formulations (example) 


\subsection{Höhn et al. approach}

This approach is thoroughly explained in $[6,12,14]$. The fundamentals applied in this calculation are those explained previously, nevertheless some approximations are assumed: i) the constant friction coefficient and ii) the analytically predefined $L S$.

As stated, the power losses were obtained using Equation 5. When the first approximation is taken into account $\left(\mu_{m}\right)$, Equation 5 becomes:

$P_{\text {loss }}=\mu_{m} \frac{F_{\text {tmax }}}{\cos (\varphi)} \frac{V}{\theta_{N}} \int_{\theta_{A}}^{\theta_{E}} \frac{F_{N}(\theta) V_{s}(\theta)}{F_{N \max } V} d \theta$

The power loss factor, which includes the power losses during the whole constant, is defined $\left(H_{v}\right)$ as:

$H_{v}=\frac{1}{\cos (\varphi) \theta_{N}} \int_{\theta_{A}}^{\theta_{E}} \frac{F_{N}(\theta) V_{s}(\theta)}{F_{N \max } V} d \theta$

Combining 7 and 8, the power losses become:

$P_{\text {loss }}=\mu_{m} F_{\text {tmax }} V H_{v}=P_{i n} \mu_{m} H_{v}$

It is clear the power loss factor depends on the $S V$ factor and the $L S R$. The $S V$ factor is a parameter defined kinematically, therefore the $L S R$ is the parameter which defines the power loss factor in this approach. According to the ISO/TC-60 standard [7], the $L S R$ approximation adopted is the uniform $L S$ where the load is half the transmitted load while in doublecontact (Figure 1, ISO/TC-60 curve). Substituting the analytical curve on Equation 8:

$H_{v}=\frac{\pi(u+1)}{z_{1} u}\left(1-\varepsilon_{\alpha}+\varepsilon_{1}^{2}+\varepsilon_{2}^{2}\right)$

where $z_{1}$ is the number of teeth of the pinion, $u$ the gear ratio, $\varepsilon_{\alpha} \mathrm{y} \varepsilon_{1}, \varepsilon_{2}$ the contact ratio and the tip contact ratio of the pinion and the gear and $\beta_{b}$ the helix angle at the base of the cylinder. Reordering the mechanical efficiency equation 1 :

$$
\begin{aligned}
\eta=\frac{P_{\text {out }}}{P_{\text {in }}}=\frac{P_{\text {in }}-P_{\text {loss }}}{P_{\text {in }}} & =\frac{P_{\text {in }}-P_{\text {in }} \mu_{m} H_{v}}{P_{\text {in }}} \\
& =1-\mu_{m} H_{v}
\end{aligned}
$$

\subsection{Proposed approach}

This approach is based on the general fundamentals for calculating the efficiency. Starting from Equation 5 and using the $L S$ obtained from the $L C M[3-5]$, the efficiency calculation is performed.
The contact forces are obtained following the procedure of Vedmar et al. $[18,5]$, which assumes that the elastic deflections of the contact can be split into two main contributions: i) global deformation and ii) local deflection. The local deflection model is based on the Hertzian contact theory, and the global deformation model, which involves the remaining deformations (deflections resulting from bending, shear and rotation), is performed using the $F E$ theory.

Deflection Calculation The global deformations are obtained using a FE model which involves the deflections resulting from bending, shear and rotation. This model provides the gear body structural deformation. Moreover, this model takes into account the deflections that the tooth in contact generates in the rest of the body (Figure 2 at the top). This effect is crucial in the efficiency analysis because the effective contact ratio is affected by this fact.

As stated, only the global deflections are sought after with this model. The contact load applied in the FE model is a point load when a distributed load is required (achieved using the Weber-Banashek model [19, $5])$. Thus, the local region is affected by this point load as is evident in Figure 2 (at the bottom on the left). To avoid this issue and twice taking into account the local model (one using the $F E$ model and the other the Weber-Banashek formulation), a partial model of the affected region of the teeth is added to the global model but with the opposite sign (Figure 2 at the bottom in the middle). In this way, the distortion introduced by the point force is ignored and, moreover, the local effect of the distributed load can be performed by another model without interference between models.

The local deflection formulation is the Weber-Banashek proposal $[19,5]$ (Figure 3) in which the deflection between a point which is located on the surface, and the other point, which is located " $h$ " units away from it. $u_{l o c}$ can be calculated using Equation 12.

$$
\begin{aligned}
& u_{l o c}(q)=\frac{2\left(1-v^{2}\right) q}{\pi E}\left[\ln \left(\frac{h}{L}+\sqrt{1+\left(\frac{h}{L}\right)^{2}}\right)\right] \\
& -\frac{2\left(1-v^{2}\right) q}{\pi E}\left[\frac{v}{1-v}\left(\frac{h}{L}\right)^{2}\left(\sqrt{1+\left(\frac{h}{L}\right)^{2}}-1\right)\right]
\end{aligned}
$$

where $q$ is the load per unit length, $E$ Young's modulus, $v$ Poisson's coefficient and $2 L$ is the length of the pressure distribution surrounding the load location, obtained using a formula that depends on the load, the geometrical parameters and the materials of the bodies (Equation 13). 


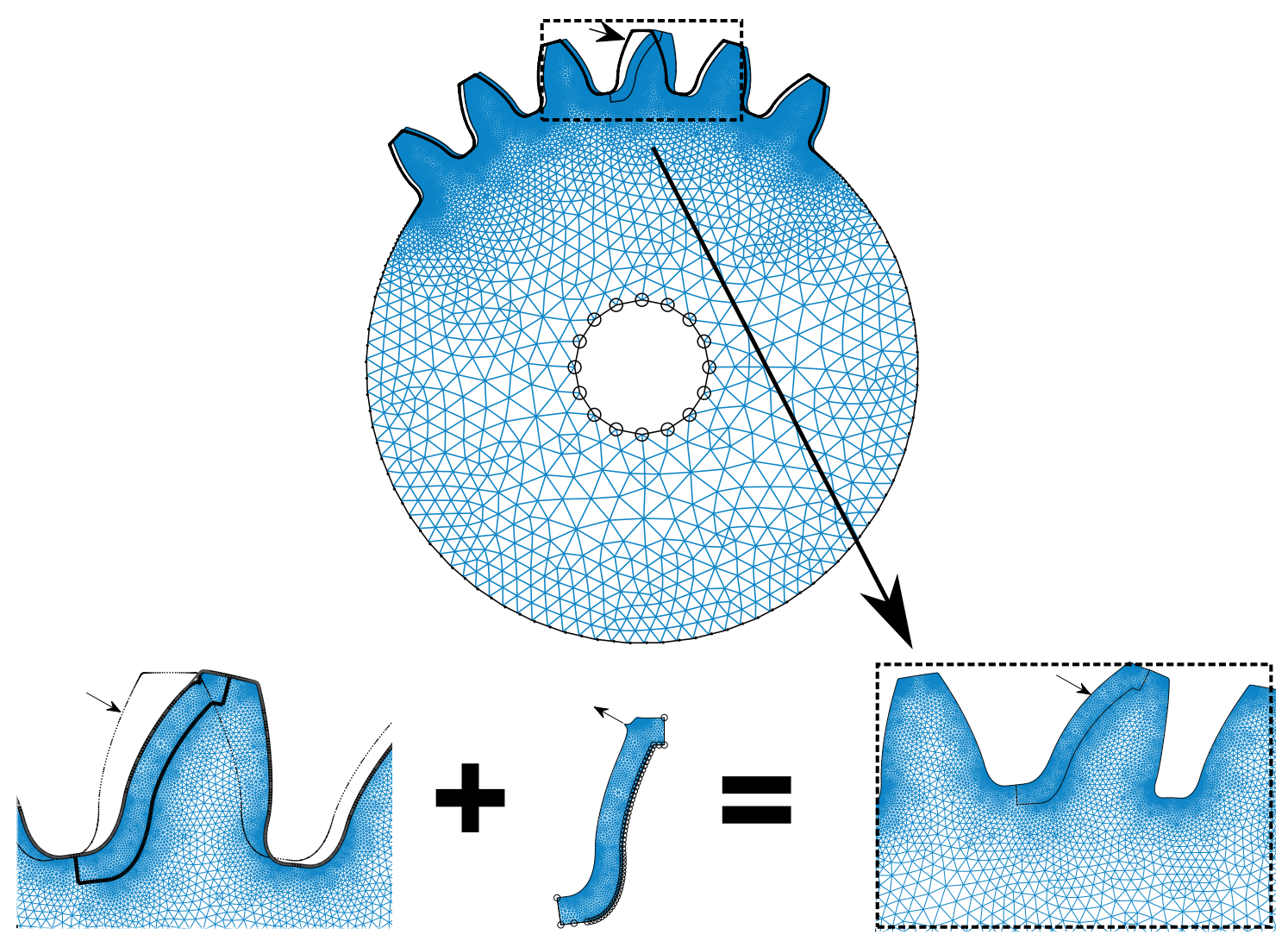

Fig. 2: Global deformation model

$L=\sqrt{\frac{4}{\pi}\left(\frac{1-v_{1}^{2}}{E_{1}}+\frac{1-v_{2}^{2}}{E_{2}}\right) \frac{\chi_{1} \chi_{2}}{\chi_{1}+\chi_{2}} q}$

where $\chi_{1}$ and $\chi_{2}$ are the curvature radii of the pinion and the driven gear respectively.

Contact Forces Calculation Once the deformation matrix is defined, the applied loads are obtained. The procedure for calculating the load consists of:
First, the deformation matrix of the system $[\lambda(q)]_{N}$ is reduced to the deformation matrix of the teeth in contact $[\lambda(q)]_{n}$. This step is reached using the geometrical overlap of the teeth (calculated using the global deformation model), from which we know which teeth are in contact and which are not.

Second, the linear problem is solved using Equation 14, from which an initial guess of the contact forces is obtained.
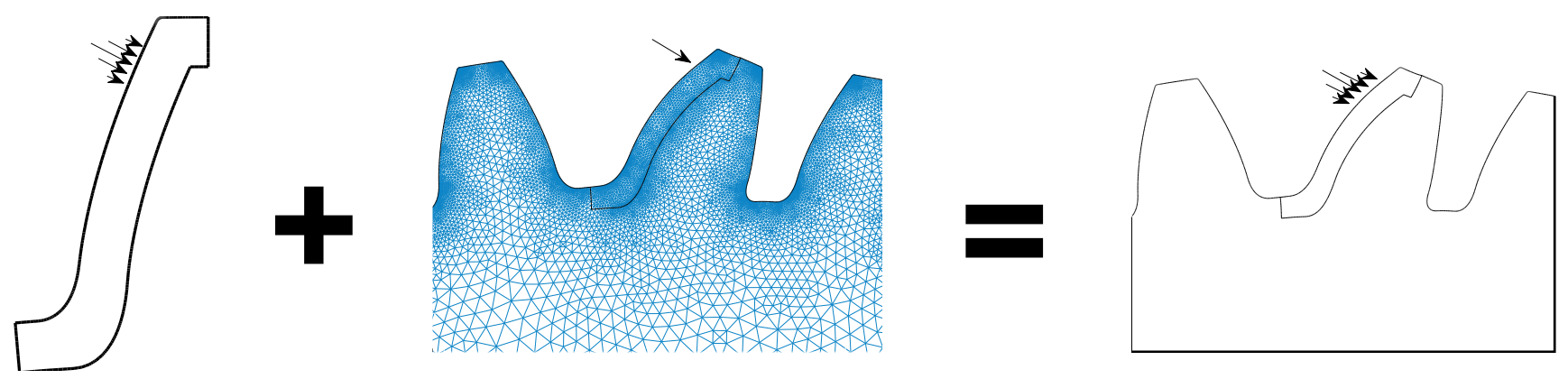

Fig. 3: Total deflections by the sum of the local and global deflection model 


$$
\{F\}_{n}=\left([\lambda(q)]_{n}\right)^{-1}\{\delta\}_{n}
$$

It can be seen that this first solution is the body stiffness $\left([\lambda(q)]_{n}^{-1}\right)$ multiplied by the geometrical over$\operatorname{lap}\left(\{\delta\}_{n}\right)$.

Third, the non-linear problem, in which the initial force value is that obtained using Equation 14, is solved iteratively. The problem is solved once the equilibrium of the forces and torques of the system is reached, checking at the same time whether new contacts have occurred.

It can be appreciated that whilst in Equation 14 only the $F E$ deflections are considered, in Equation 15 both the local and global deflections are considered.

$$
\begin{aligned}
\{\delta\}_{n}=\{ & \left.u_{\text {local }}^{\text {pinion }}\left(q,\{F\}_{n}\right)\right\} \\
& +\left\{u_{\text {local }}^{\text {gear }}\left(q,\{F\}_{n}\right)\right\}+[\lambda(q)]_{n}\{F\}_{n}
\end{aligned}
$$

The above procedure is summarized in the block flow diagram of Figure 4.

It must be highlighted that the system equilibrium is reached when the resistive torque is equal to the torque generated by the different forces in the conjunction. To reach this equilibrium, only normal forces are usually considered [15], nevertheless, in the $L C M$, the friction forces were also taken into account. This fact has a major consequence in the $L S$ distribution, a step in the single contact region takes place as can be observed from the comparative of $L S R$ showed in Figure 1 ( $L C M$ with and without friction). The reason why this step occurs is that before the pitch point, the torque due to the friction force is opposed to the movement, hence, has opposite sign to the normal force torque, whilst after the pitch point, both torques have the same direction. This happens because the friction force depends on the sliding velocity direction.

\section{Results and Discussion}

As stated before, the main objective of this work is to study the influence of shifting profile on the energy efficiency of spur gear transmissions. Since the introduction of shifting has a major impact on the $L S$ distribution, and the $L S$ greatly affects the efficiency of the system, the first results to be presented consist on the comparison between $L S$ formulations when there was no shifting (shown in Figure 5).

When the two approaches were compared in the null-shift coefficient case (Figure 5), it can be seen that only $L S$ changed and was clear how this variation influenced the Instantaneous Power Loss (IPL) factor.

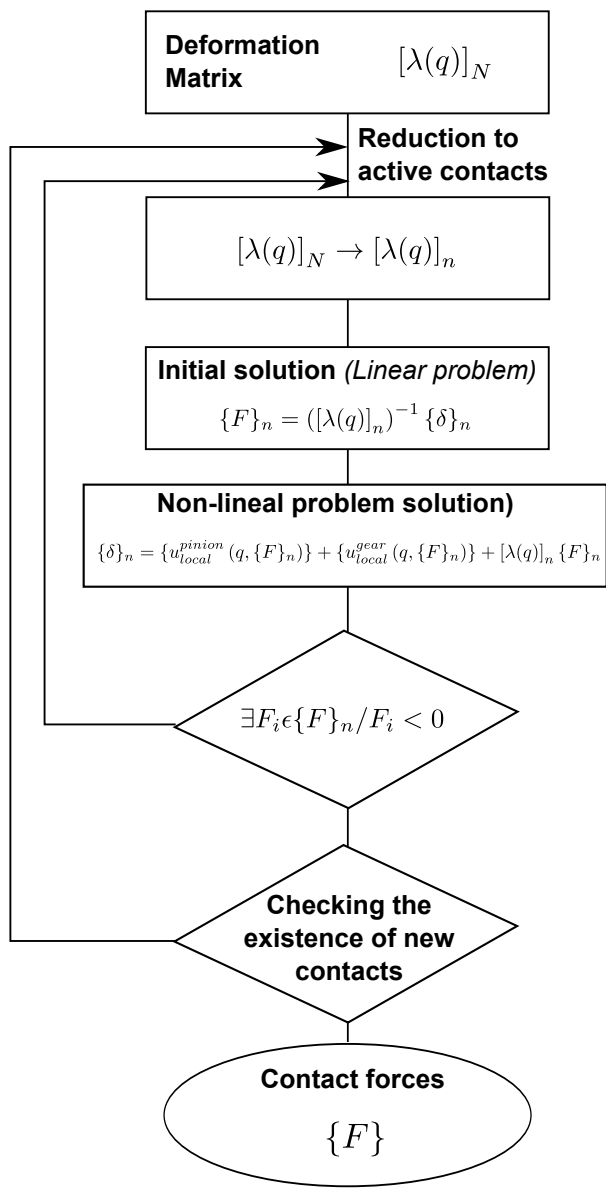

Fig. 4: Procedure for calculating contact forces
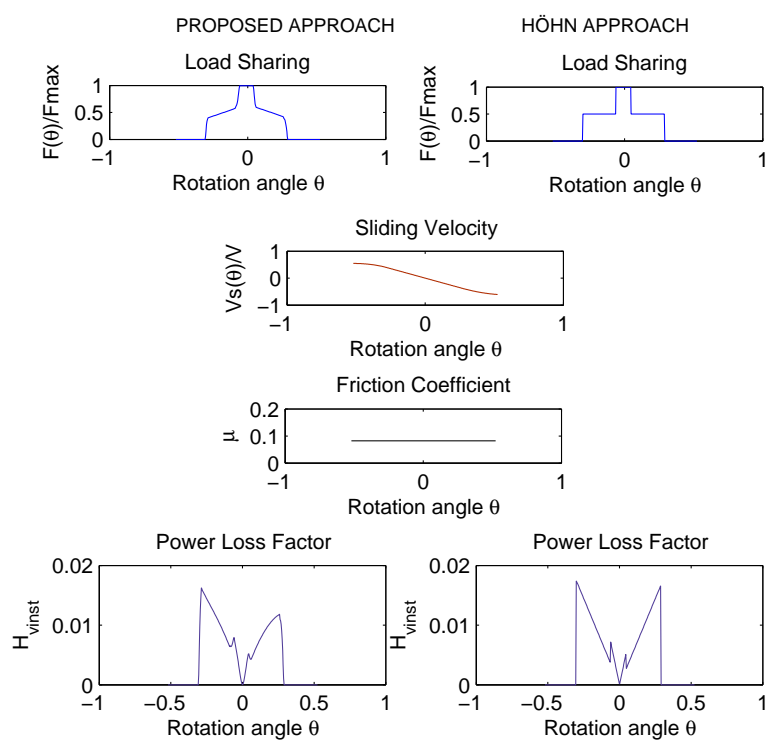

Fig. 5: Comparison between both approaches. Load sharing, sliding velocity, friction coefficient and power loss factor 
This $L S$ difference between the approaches showed a variation in the shape of the $I P L$ factor and therefore on the efficiency.

As the $L C M$ developed by the authors took into account the deflection of teeth, a longer path of contact was evident in the proposed approach with respect to the Höhn's one, and therefore an increase in the power losses occurred. This meant that when a pair of gear teeth was in contact, the deflection produced by this pair affected the remaining teeth. It turned out that the start of the contact with the next tooth took place sooner than for the kinematical case and that the end of the contact took place later than the theoretical case. Moreover, because of the $L C M$, the double-contact region in the numerical approach was not uniform. In fact, it was clear that the gear pair supported a lower load when the contact started and finished than that shown analytically. Regarding the IPL factor, it was evident that the parts of the contact in which more power losses were produced were at the beginning and end of the contact. This was because the sliding velocity in this region was significantly higher than in the pitch point region.

Once the influence of the $L S$ formulation on the efficiency was assessed, the effect of the shifting profile on the efficiency was analysed. To this end, three different scenarios were designed, namely, (i) fixed exterior radii, (ii) fixed theoretical contact ratio and (iii) exterior radii dependent on the shift coefficient. The working parameters used in all the scenarios are presented in Table 1. These parameters were used by Baglioni et al. [2] to calculate the efficiency using the Höhn approach. In this study, the Baglioni et al. efficiency results were used as a reference and compared with those obtained using the proposed approach.

Table 1: Operating conditions and pinion/gear parameters

\begin{tabular}{|c|c|c|c|}
\hline $\begin{array}{l}\text { No. of pinion } \\
\text { teeth }\end{array}$ & 18 & Module & $3 \mathrm{~mm}$ \\
\hline $\begin{array}{c}\text { No. of gear } \\
\text { teeth }\end{array}$ & 36 & Face width & $26.7 \mathrm{~mm}$ \\
\hline Pressure angle & $20^{\circ}$ & $\begin{array}{c}\text { Mean } \\
\text { Roughness }\end{array}$ & $0.8 \mu \mathrm{m}$ \\
\hline $\begin{array}{c}\varepsilon_{\alpha} \text { (without } \\
\text { shifting) }\end{array}$ & 1.611 & $\begin{array}{c}\text { Centre } \\
\text { distance }\end{array}$ & $81 \mathrm{~mm}$ \\
\hline$d d_{h t a}$ & 1 & $a d_{h t a}$ & 1.25 \\
\hline $\begin{array}{l}\text { Operating } \\
\text { conditions }\end{array}$ & Power(kW) & Torque(Nm) & Speed(rpm) \\
\hline $\mathrm{OC} 1$ & 25 & 159 & 1500 \\
\hline $\mathrm{OC} 2$ & 25 & 40 & 6000 \\
\hline OC3 & 50 & 159 & 3000 \\
\hline $\mathrm{OC} 4$ & 100 & 637 & 1500 \\
\hline OC5 & 100 & 159 & 6000 \\
\hline
\end{tabular}

Three scenarios were performed to assess the effect of the shifting profile in five different operating conditions $(\mathrm{OC} 1 \div \mathrm{OC} 5)$. In the first a fixed exterior radius for the gear and pinion was established. The aim was to evaluate the effect of shifting without varying the contact ratio of the system. A second study was performed because the influence of shifting was not evident for the small range of the shifting profile coefficient considered in the first study (mesh interference occurred when a large value of the shift coefficient was used). In this second study, a fixed contact ratio between the gears was considered. The exterior radii of both the pinion and driven gear were calculated taking into account this constraint. In the third study, the shifting profile was assessed taking into account that the exterior radius varied with the shift coefficient. The aim was to evaluate the combination of the shifting coefficient and the contact ratio effects on the $L S$ and therefore on the efficiency.

\subsection{FIRST STUDY: FIX EXTERIOR RADIUS}

In this first study the efficiency values obtained using both approaches when the exterior radii were fixed were compared. In Figure 6 the efficiency values for several shift coefficients and operating conditions are shown.

All the differences between approaches in the nullshift case were aggravated when the shifting was introduced and turned into a deviation in the efficiency values as shown in Figure 6. Although this efficiency value dispersion was acceptable, as can be seen in the same figure, this difference was emphasized when the resistant torque was higher (OC4 case). This occurred mainly because of the deflection of teeth in the $L C M$ and therefore because of the effective contact ratio. Understanding the effective contact ratio involved the contact ratio calculated taking into account other factors such as torque and speed, in addition to the geometrical factors considered in the theoretical contact ratio. The comparison between the theoretical and effective contact ratios in the two different operating conditions is presented in Figure 7 to illustrate the deviation between them.

In Figure 7, it can be observed that the contact ratio difference in the least severe conditions (OC2) was negligible while in the worst conditions (OC4) it was considerable. Considering the contact ratio deviation and observing the efficiency values (Figure 6), it can be said that the effect of the uniform $L S$ was counteracted by the contact ratio effect when the torque was 159 Nm (OC1, OC3 and OC5) because the efficiency values for both approaches were similar. Nevertheless, with the lowest torque value, it can be seen that the Höhn 


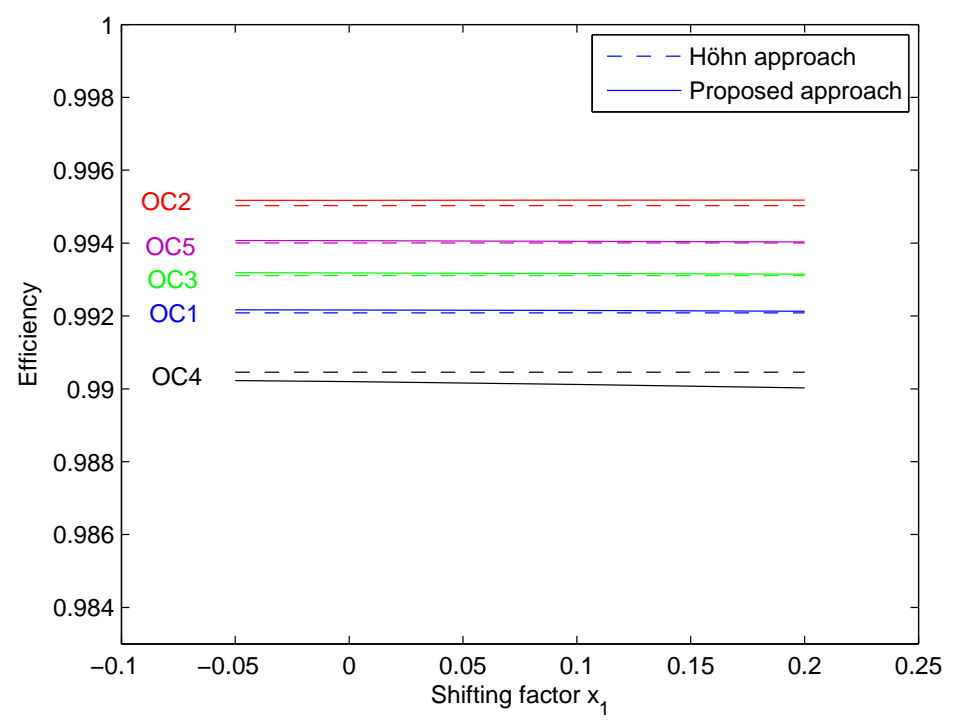

Fig. 6: Comparison, between both approaches, of the efficiency values for several shift coefficients and operating conditions (Exterior Radii Fixed)
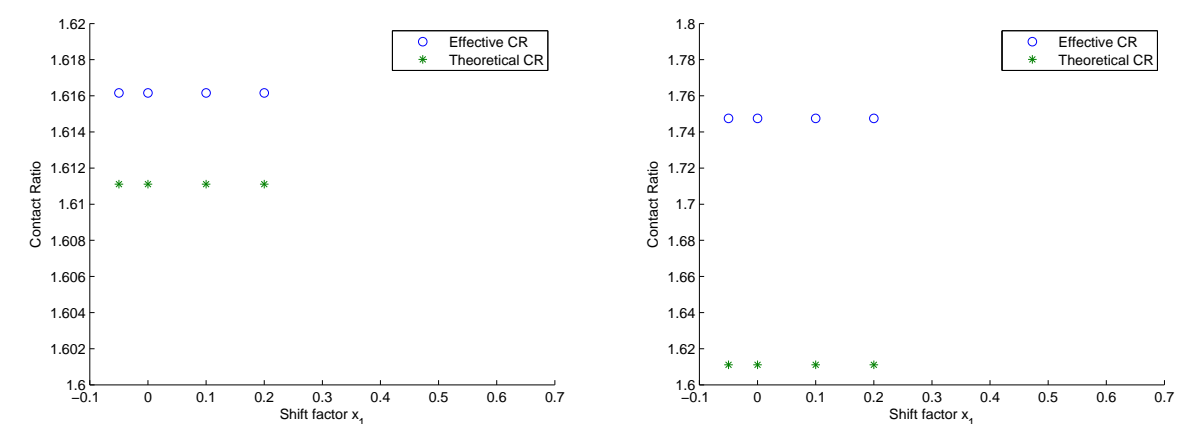

(a) Contact Ratio OC2 (Exterior Radii (b) Contact Ratio OC4 (Exterior Radii Fixed) Fixed)

Fig. 7: Contact Ratio comparison between approaches in operating conditions 2 and 4

approach had lower efficiency values. This occurred because the power losses resulting from the uniform $L S$ at the start and end of the contact were bigger than those produced using the numerical $L S$ and adding the contact ratio effect. This meant that the contact ratio effect was small (small difference between the theoretical and the effective contact ratio) with respect to the difference in the $L S$ effect, and the contrary in the OC4 case because the proposed approach efficiency values were bigger than the Höhn efficiency values. From this point forward, although a general comparison is performed, only the operating conditions 2 and 4 will be shown in the figures because they are the extreme operating conditions considered.

It can be appreciated in Figure 8 that the shifting profile had an influence on the $L S$ shape, making the load transmitted in the double-contact region different depending on whether the contact was at the start or the end.

This behavior had an impact on the efficiency value that was not well understood, because only a small range of shift coefficient was assessed. The reason a small range of shift coefficient was considered was that mesh interference occurred when a large value of the shift coefficient was used. This occurred because the interior radius of the involute curve increased with the shift coefficient while the exterior radii were constrained, turning into a contact in the trochoid profile which was not desirable. With regard to the impact on the efficiency value resulting from the shifting profile, a slight difference between efficiency values in the same operat- 

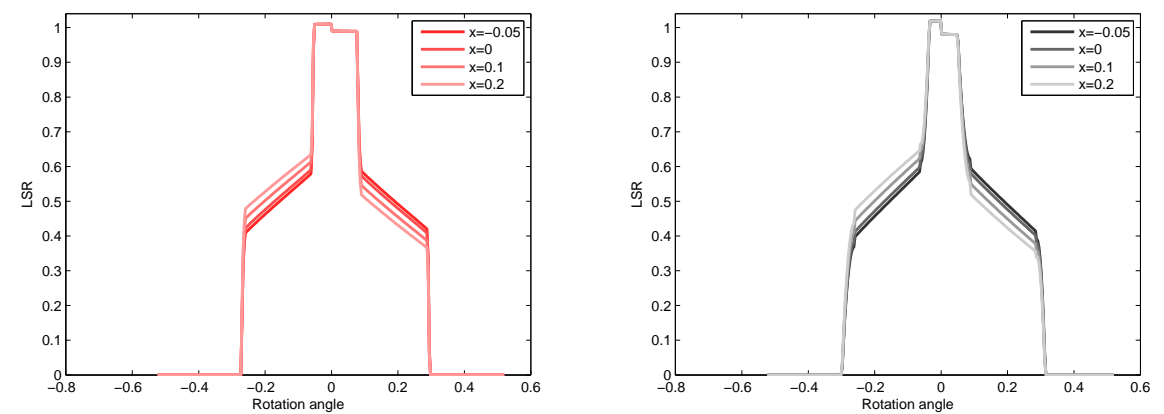

(a) Load Sharing OC2 (Exterior Radii (b) Load Sharing OC4 (Exterior Radii Fixed)

Fixed)

Fig. 8: Numerical Load Sharing for different shift coefficients (OC2 and OC4)

ing conditions was appreciated. This was assessed using the $I P L$ factors presented in Figure 9.

To assess the impact of the operating conditions on efficiency, the IPL factors in the different operating conditions are shown in Figure 10. As a general rule, it was deduced from the figure that the higher the torque, the more power losses were produced, obtaining the same effect when the speed decreased. Moreover, the higher the torque, the bigger the contact ratio. These turned into greater power losses and therefore into small efficiency values.

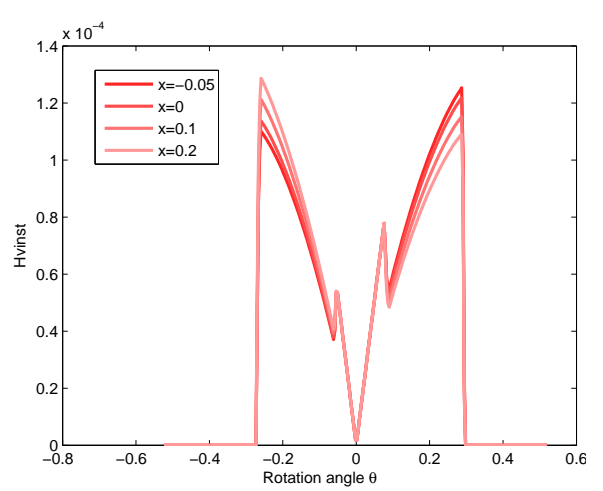

(a) $H_{\text {vinst }}$ OC2 (Exterior Radii Fixed)

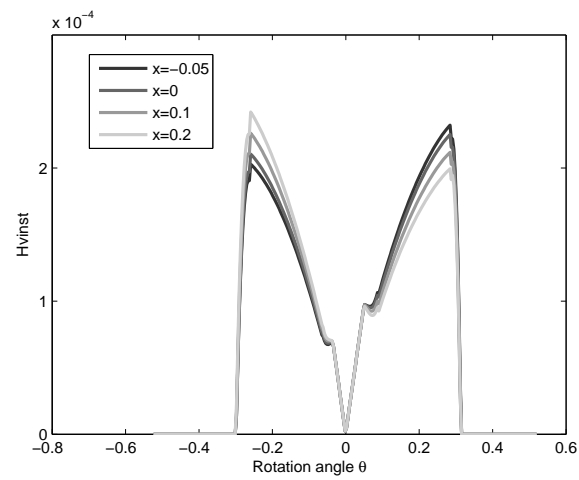

(b) $H_{\text {vinst }}$ OC4 (Exterior Radii Fixed)

Fig. 9: Instantaneous Power Loss factor for different shift coefficients (OC2 and OC4)

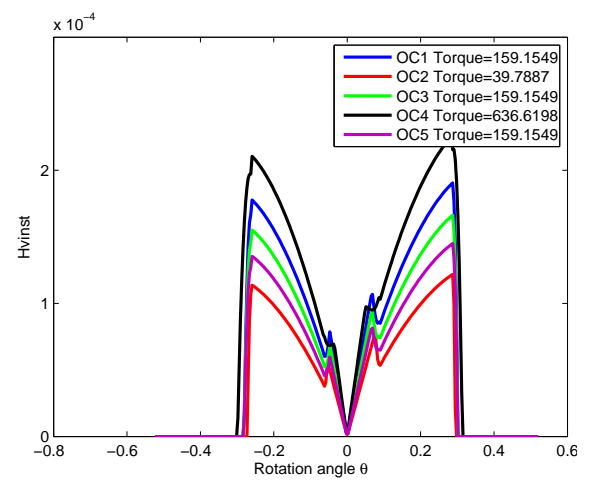

(a) $H_{\text {vinst }} x_{1}=0$ (Exterior Radii Fixed)

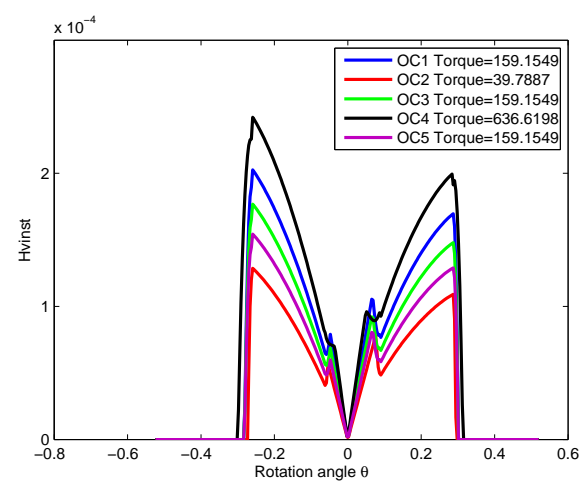

(b) $H_{\text {vinst }} x_{1}=0.2$ (Exterior Radii Fixed)

Fig. 10: Instantaneous Power Loss factor for different operating conditions $\left(x_{1}=0\right.$ and $\left.x_{1}=0.2\right)$ 
In addition, it was observed that the level of efficiency depended mainly on the level of the torque. This agreed with Figure 6 and therefore Figure 10 where, for the lowest torque $(40 \mathrm{Nm})$, the highest efficiency level was reached, for the medium torque level $(159 \mathrm{Nm})$ the medium efficiency level was reached and with the highest torque $(637 \mathrm{Nm})$ the lowest efficiency level was obtained. Nevertheless, it was evident that for the same torque, a lower speed turned into a decrease in efficiency.

\subsection{SECOND STUDY: FIXED THEORETICAL CONTACT RATIO}

As the influence of the shifting was not evident for the small range of the profile shift coefficient considered in the first study, the efficiency values obtained by both approaches varying the exterior radii were compared in this second study. To avoid the small range issue, the exterior radius of both the pinion and driven gear for each case of shift coefficient was calculated, taking into account a constant contact ratio. This constraint was assumed because only the shifting profile effect on the efficiency was to be assessed. Otherwise, if this had not been considered, the contact ratio variation effect would have been confused with the shift coefficient effect. The evaluation of the combination of these two effects was the aim of the third study, being the assessment of the second effect isolated from the first one, the objective of this scenario.

The considered contact ratio $\left(\epsilon_{\alpha}\right)$ in this part of the study was always 1.611, which corresponded to the nullshift coefficient case. The methodology to determine the exterior radius of the pinion and the gear for each case was as follows:

First, the exterior radius of the pinion $\left(R_{1 e x t}\right)$ was calculated using Equation 16:

$R_{1 e x t}=m\left(\frac{z_{1}}{2}+x_{1}+d d_{h t a}\right)$

where $m$ is the modulus, $z_{1}$ the number of teeth for the pinion, $x_{1}$ the profile shift coefficient of the pinion and $d d_{h t a}$ the dedendum of the cutter.

Second, with the exterior radius of the pinion, the tip contact ratio of the pinion $\left(\varepsilon_{1}\right)$ was calculated by:

$\varepsilon_{1}=\frac{\sqrt{R_{1 e x t}^{2}-\left(R_{1} \cos (\varphi)\right)^{2}}-R_{1} \sin (\varphi)}{\pi m \cos (\varphi)}$

Because the contact ratio was the sum of both the tip contact ratios, the tip contact ratio of the driven gear was obtained by: $\varepsilon_{2}=\varepsilon_{\alpha}-\varepsilon_{1}$

Finally, the exterior radius of the driven gear $\left(R_{2 e x t}\right)$ was obtained using:

$R_{2 e x t}=\sqrt{\left(R_{2} \sin (\varphi)+\varepsilon_{2} \pi m \cos (\varphi)\right)^{2}+\left(R_{2} \cos (\varphi)\right)^{2}}$

Once the methodology to calculate the exterior radii was established, the efficiency values for several shift coefficients and operating conditions were obtained, as shown in Figure 11.

In Figure 11, it can be observed that the efficiency values decreased as long as the shift coefficient increased (first statement). Moreover, the larger the shift coefficient, the larger the efficiency difference between approaches (second statement).

To understand why the first statement is valid, Figure 12 and Figure 13, which show the $L S$ and $I P L$ factor for the different values of shift coefficient, are presented.

It can be appreciated that the contact length was always the same but it gave the impression that it was "moving" to the left as the shift coefficient increased. This occurred because when the shift coefficient increased, the start and end points were reached sooner. In the same way, the load transmitted at the beginning of the contact also increased while at the end it decreased. Moreover, the single-contact region took place out of the pitch point region where the sliding velocity was no longer zero. All this resulted in greater power losses providing the shift coefficient increased, explaining why the efficiency decreased with an increment in the shift coefficient. To demonstrate this, Figure 14 is presented, which shows the IPL factor for both approaches in two shift coefficient cases $(\mathrm{x}=0$ and $\mathrm{x}=0.5)$ and OC4 (only OC4 is shown for the sake of clarity). It can be observed that when the shift coefficient was zero, the area under the continuous curve was smaller than for the 0.5-shift coefficient case, and the same was achieved for the dash curve. Thus, this statement was achieved in both approaches.

In the same figure (Figure 14), to assess the deviation between approaches (the second statement), the area between the continuous and dashed curves showed the power losses that the proposed approach considered and the Höhn approach did not. Considering this, it was seen that while in the 0 -shift coefficient case the sum of the negative and positive areas was close to zero, in the 0.5 -shift coefficient case the power losses considered by the proposed approach were greater than the Höhn power losses. This indicates that the higher the shift coefficient, the greater the deviation between approaches. 


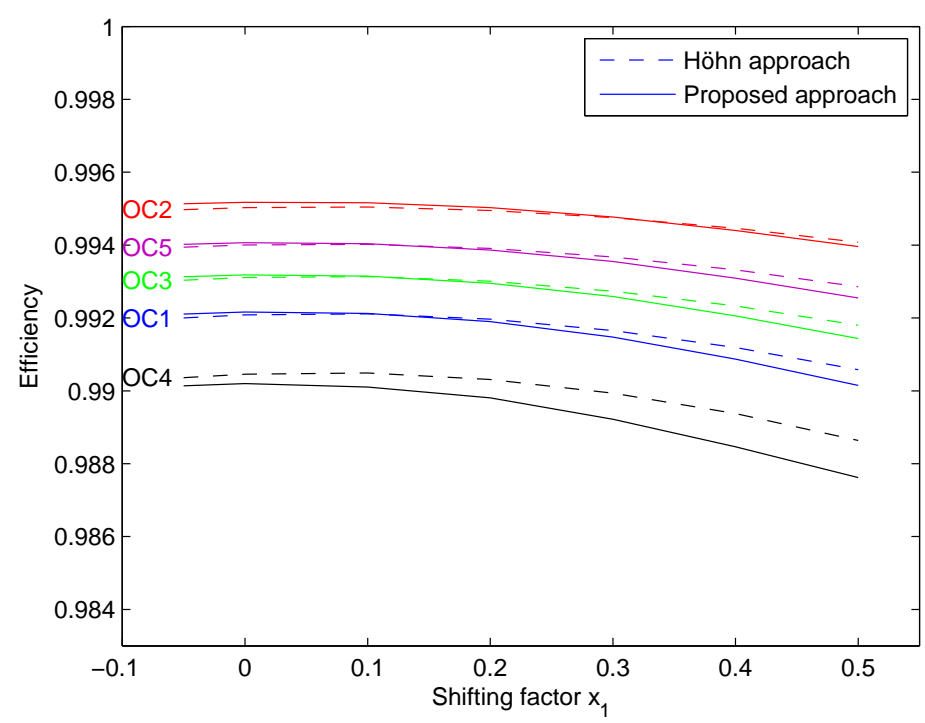

Fig. 11: Comparison, between both approaches, of the efficiency values for several shift coefficients and operating conditions (Contact Ratio Fixed)
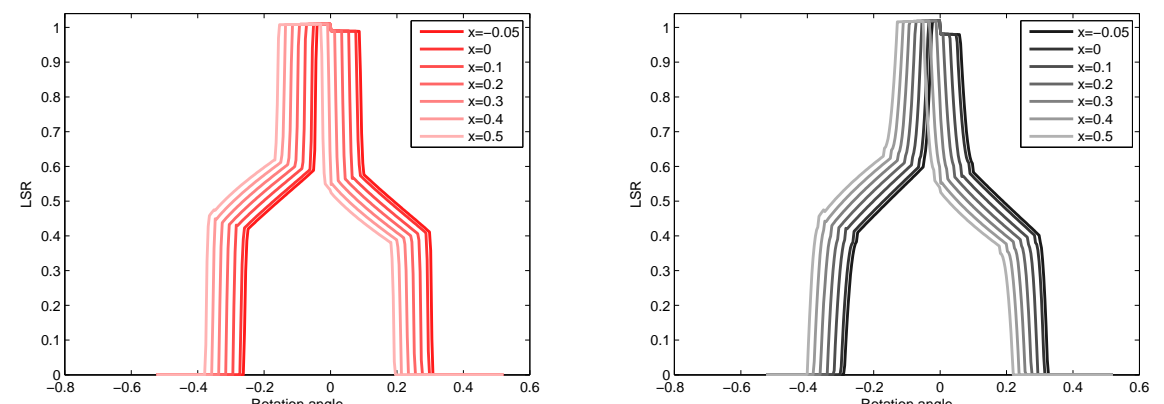

(a) Load Sharing OC2 (Contact Ratio (b) Load Sharing OC4 (Contact Ratio Fixed) Fixed)

Fig. 12: Load sharing for different shift coefficients (OC2 and OC4)

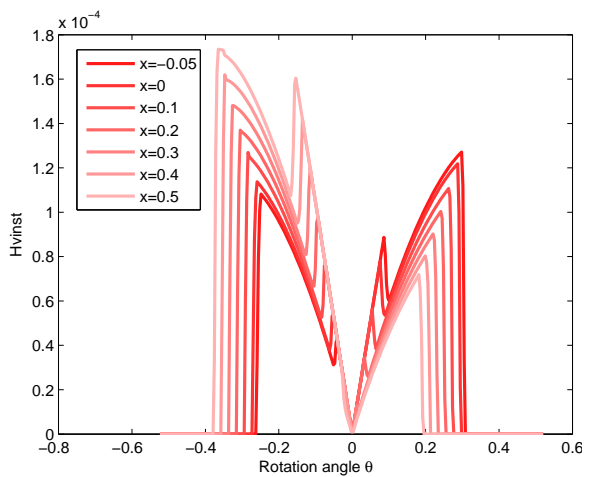

(a) $H_{\text {vinst }}$ OC2 (Contact Ratio Fixed)

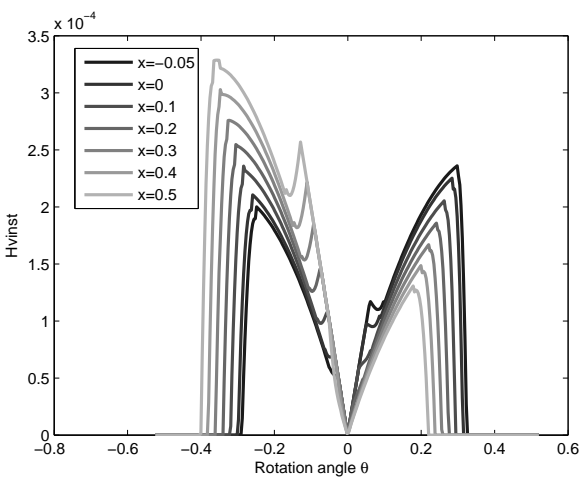

(b) $H_{\text {vinst }}$ OC4 (Contact Ratio Fixed)

Fig. 13: Instantaneous Power Loss factor for different shift coefficients (OC2 and OC4) 

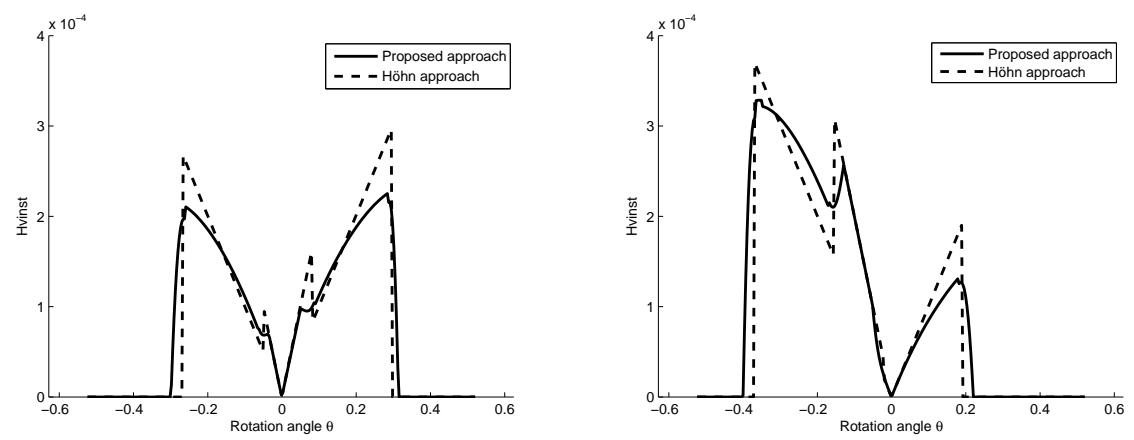

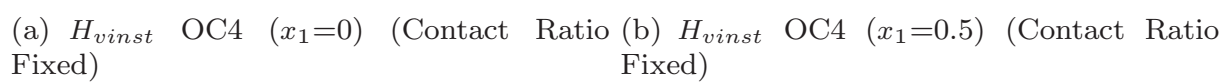

Fig. 14: Instantaneous Power Loss factor for different shift coefficients $\left(x_{1}=0\right.$ and $\left.x_{1}=0.5\right)$ and operating conditions (OC2 and OC4)

As in the previous study, to assess the impact of the operating conditions on the efficiency, the IPL factors in the different operating conditions are shown (Figure 15). The general rules articulated in the previous sections continue to hold true.

\subsection{THIRD STUDY: EXTERIOR RADII DEPEND ON THE SHIFT COEFFICIENT}

A comparison between the efficiency values obtained using both approaches was performed in this third study. The aim of the study was to assess both the contact ratio and shifted profile effect on efficiency. To observe both effects, the exterior radii of both gears, as well as the shift coefficient, were varied, showing that the contact ratio varied in each case. The exterior radii of both gears were calculated as:

$$
R_{1 e x t}=m\left(\frac{z_{1}}{2}+x_{1}+d d_{h t a}\right)
$$

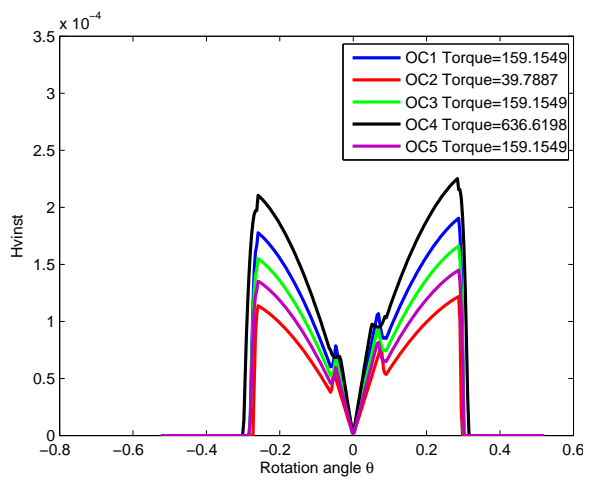

(a) $H_{\text {vinst }} x_{1}=0$ (Contact Ratio Fixed)

$$
R_{2 e x t}=m\left(\frac{z_{2}}{2}+x_{2}+d d_{h t a}\right)=m\left(\frac{z_{2}}{2}-x_{1}+d d_{h t a}\right)
$$

First, the Höhn and proposed approaches were compared. The efficiency values are presented in Figure 16.

From the figure, the same outcome was deduced as in the previous study. The efficiency values decreased and the difference between approaches increased providing the shift coefficient increased. Although the same conclusions as in the previous study were reached, to comprehend why this occurred and what the differences between the studies were, Figure 17 and Figure 18 are presented.

Once again, the shifted profile and the contact ratio effects on the efficiency were assessed. Up to this point, the latter was neglected in order to assess only the former. Regarding the profile shifting, in the Figures 17 and 18, it was evident that the contact started and ended sooner providing the shift coefficient was increasing. This gave the impression that the contact was

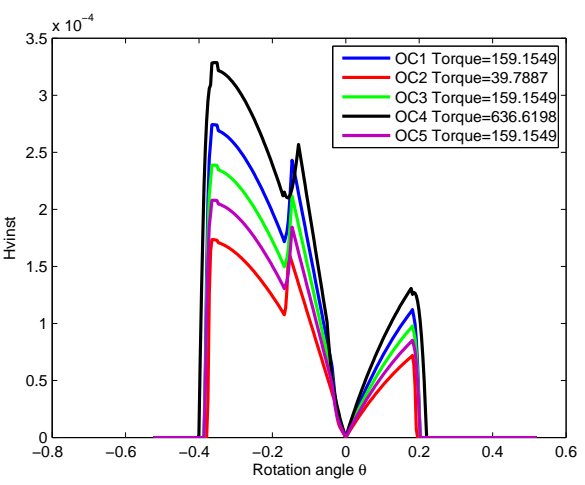

(b) $H_{\text {vinst }} x_{1}=0.5$ (Contact Ratio Fixed)

Fig. 15: Instantaneous Power Loss factor for different operating conditions $\left(x_{1}=0\right.$ and $\left.x_{1}=0.5\right)$ 


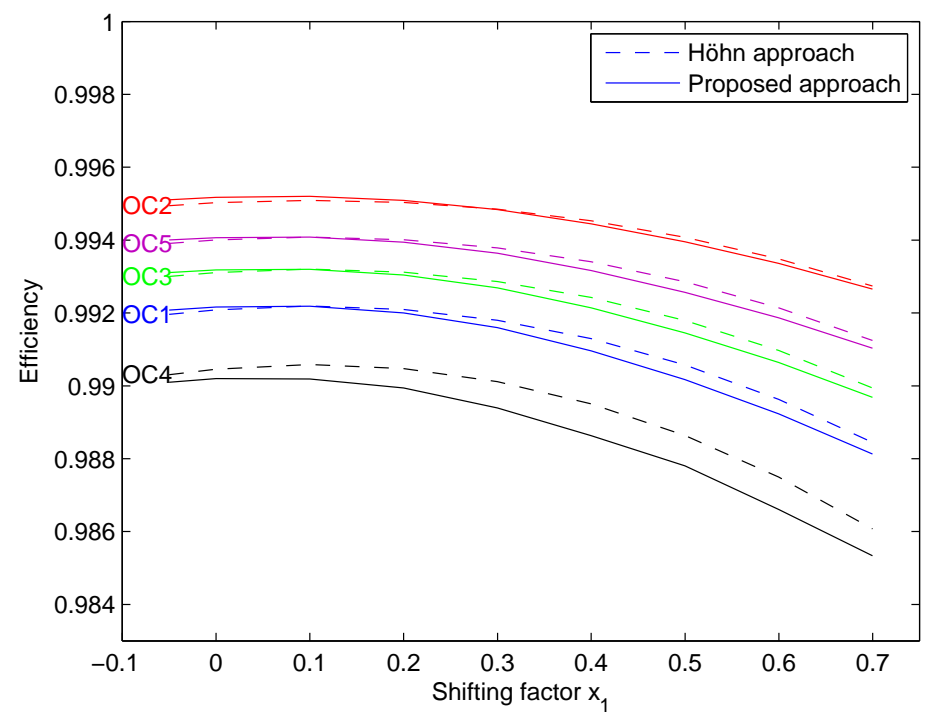

Fig. 16: Comparison between both approaches of the efficiency values for several shift coefficients and operating conditions

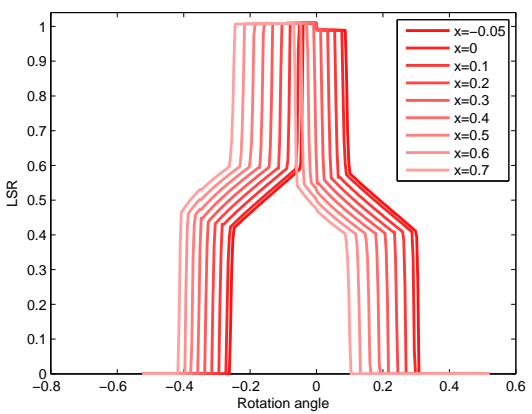

(a) Load Sharing OC2

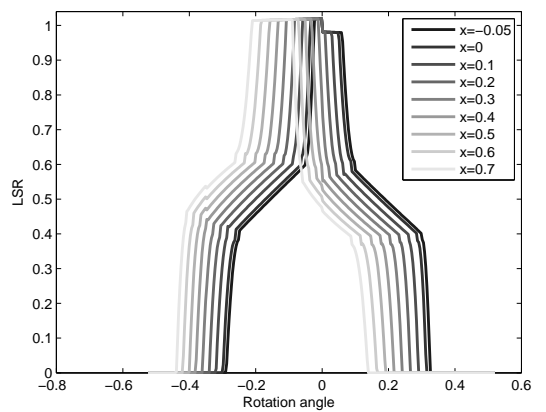

(b) Load Sharing OC4

Fig. 17: Load sharing for different shift coefficients (OC2 and OC4)

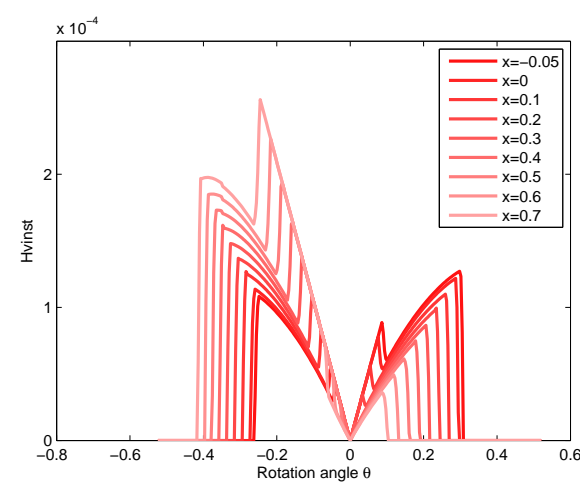

(a) $H_{\text {vinst }} \mathrm{OC2}$

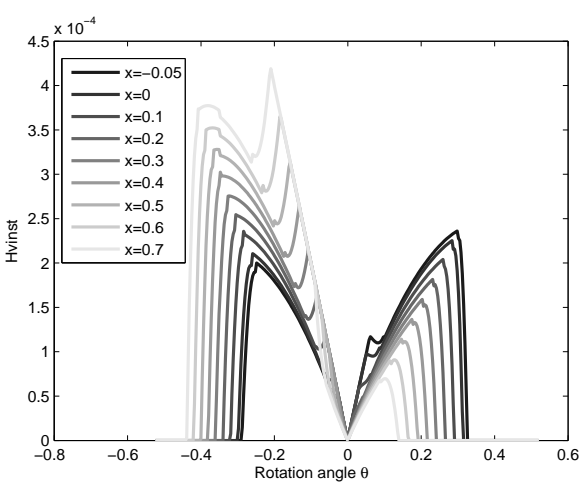

(b) $H_{\text {vinst }}$ OC4

Fig. 18: Instantaneous Power Loss factor for different shift coefficients (OC2 and OC4) 
moving to the left. Moreover, with regard to the contact ratio, the value decreased providing the shift coefficient increased. To clarify this point, Figure 19 is presented.

From Figure 19, it was deduced on the one hand why the efficiency deviation between approaches depended on the operating conditions, and on the other hand why this deviation increased with the shift coefficient. Regarding the first statement, it can be seen in Figure 16 that the efficiency deviation for the low-torque operating conditions (OC2) was small and nearly negligible whilst in the high-torque operating conditions (OC4) it was considerably higher. The explanation for this behavior is evident in Figure 19 and was related to the difference between the contact ratio values because in the $\mathrm{OC} 2$ simulation there was no difference between approaches while in the OC4 simulation one did exist. Regarding the second statement, it can be appreciated in Figure 16 that the efficiency deviation between approaches increased with the shift coefficient in all the cases. The explanation for this behavior was also related to the contact ratio and can be observed in Figure 19. The contact ratio difference between approaches increased as long as shift coefficient increased, hence, greater power losses were expected because the effective contact ratio was longer than for the theoretical contact ratio.

As in the previous study, the IPL factors in the different operating conditions are shown (Figure 20) to understand the impact of the operating conditions on the efficiency when there was no profile shifting and with the extreme case of shifting. The general rules commented in the previous sections continued to hold true.

\section{Conclusions}

In this study, an efficiency analysis of shifted spur gears was performed using the load contact model previously developed by the authors and it was compared with the efficiency values calculated using the Höhn et al. approach. Special attention was given to the profile shifting effect on the efficiency in this type of system, specifically, to the load sharing effect in the calculation of the power losses and therefore on the efficiency. The

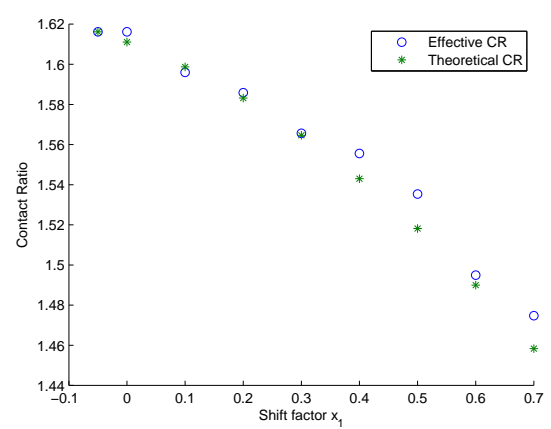

(a) Contact Ratio OC2

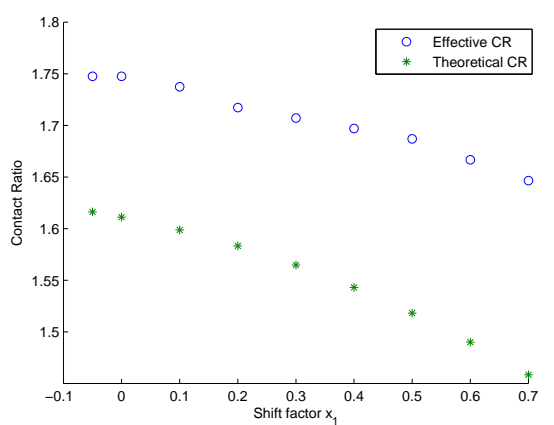

(b) Contact Ratio OC4

Fig. 19: Contact Ratio comparison between approaches in OC2 and OC4

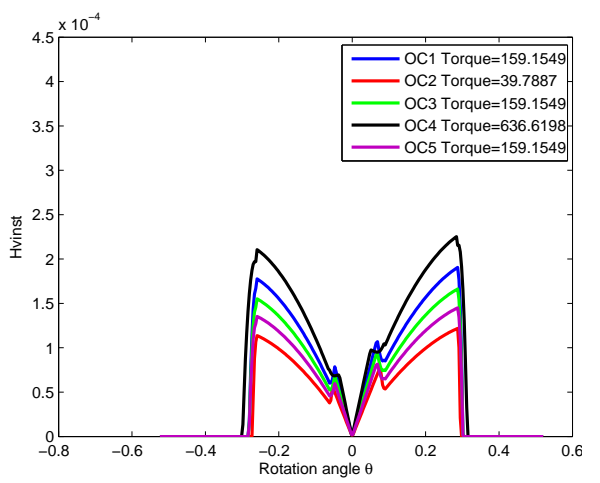

(a) $H_{\text {vinst }} x_{1}=0$

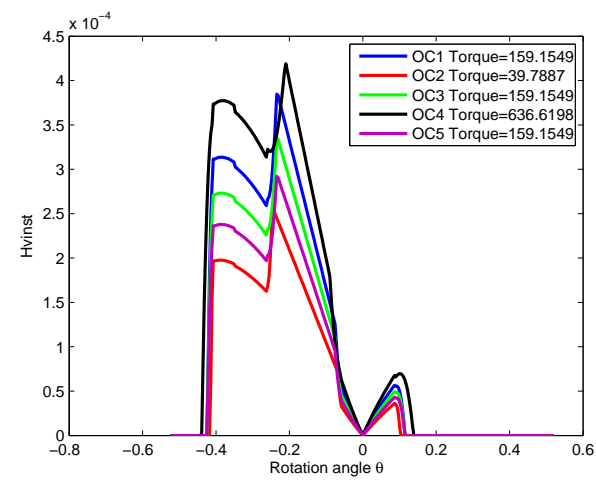

(b) $H_{\text {vinst }} x_{1}=0.7$

Fig. 20: Instantaneous Power Loss factor for different operating conditions $\left(x_{1}=0\right.$ and $\left.x_{1}=0.7\right)$ 
friction, implemented using the Coulomb's model, was modeled by the Niemann formulation with the aim of determining the influence of the frictional effects on the energy efficiency of the system. This formulation was constant along the mesh cycle, nevertheless the proposed approach allowed the use of variable friction coefficient formulations.

In this work, three scenarios were developed to assess the effect of profile shifting on the efficiency. In the first two scenarios, the aim was to evaluate the effect of the shifting itself without varying the contact ratio of the system. For this reason, in the first scenario the exterior radii of the pinion and the driven gear were fixed whilst in the second one the exterior radii of the pinion and the driven gear were calculated to meet the scenario requirements. In the third scenario, both the shifted profile and the contact ratio effects on the efficiency were considered because the exterior radii varied with the shift coefficient.

From the first and second scenarios, an important conclusion was reached. The efficiency decreased with the shift coefficient increment as a result of the load sharing variation at the beginning and end of the contact condition. Moreover, the efficiency deviation between both approaches increased when the shift coefficient increased.

From the third scenario assessment, several conclusions were reached. First, when the contact ratio and the profile shifting effects were mixed, lower efficiency than in the other two studies (where only the profile shifting effect was considered) was obtained. The statement from the previous studies was also satisfied. The higher the shift coefficient, the lower the efficiency and the higher the deviation between approaches. Moreover, the deviation between both approaches was even greater than in the previous studies because the difference between the effective and theoretical contact ratios increased with the shift coefficient.

In addition to the conclusions extracted specifically in each scenario, general conclusions were applicable to all the scenarios. When the efficiency values were compared using the proposed approach, they were generally lower than those calculated by Höhn's, because of the deflection of the teeth considered in the proposed approach. In this work, it was concluded that there was a decrease in efficiency when a high shift coefficient was used (higher than 0.3 in the case of study), that the higher the torque, the lower the efficiency, and that the higher the spin speed, the greater the efficiency. In spite of these conclusions are valid for this particular gear geometry and shift modifications (coefficients of both the pinion and the driven gears were constrained according to $x_{1}+x_{2}=0$ ), it might be extended to gears with other geometrical parameters, but further analysis would be required.

Acknowledgments The authors would like to acknowledge Project DPI2013-44860 funded by the Spanish Ministry of Science and Technology and the COST ACTION TU 1105 for supporting this research.

\section{References}

1. Anderson, N.E., Loewenthal, S.H.: Effect of geometry and operating conditions on spur gear system power loss. Journal of mechanical design 103(4), 151-159 (1981)

2. Baglioni, S., Cianetti, F., Landi, L.: Influence of the addendum modification on spur gear efficiency. Mechanism and Machine Theory 49, 216-233 (2012)

3. Fernández del Rincón, A., Iglesias, M., De-Juan, A., García, P., Sancibrián, R., Viadero, F.: Gear transmission dynamic: Effects of tooth profile deviations and support flexibility. Applied Acoustics 77(0), 138-149 (2014)

4. Fernández del Rincón, A., Viadero, F., Iglesias, M., DeJuan, A., García, P., Sancibrian, R.: Effect of cracks and pitting defects on gear meshing. Proc IMechE Part C: J Mechanical Engineering Science 226(11), 2805-2815 (2012)

5. Fernández Del Rincón, A., Viadero, F., Iglesias, M., García, P., De-Juan, A., Sancibrian, R.: A model for the study of meshing stiffness in spur gear transmissions. Mechanism and Machine Theory 61, 30-58 (2013)

6. Höhn, B.R.: Improvements on noise reduction and efficiency of gears. Meccanica 45(3), 425-437 (2010)

7. ISO 6336-1:1996: Calculation of load capacity of spur and helical gears. International Organization for Standardization (1996)

8. Kuria, J., Kihiu, J.: Prediction of overall efficiency in multistage gear trains. World Academy of Science, Engineering and Technology 74, 50-56 (2011)

9. Litvin, F.L., Fuentes, A.: Gear Geormetry and Applied Theory, second edition edn. Cambridge University Press. (2004)

10. Martin, K.F.: A review of friction predictions in gear teeth. Wear 49(2), 201-238 (1978)

11. Martins, R., Seabra, J., Brito, A., Seyfert, C., Luther, R., Igartua, A.: Friction coefficient in fzg gears lubricated with industrial gear oils: Biodegradable ester vs. mineral oil. Tribology International 39(6), 512-521 (2006)

12. Michaelis, K., Höhn, B.R., Hinterstoißer, M.: Influence factors on gearbox power loss. Industrial Lubrication and Tribology 63(1), 46-55 (2011)

13. Mucchi, E., Dalpiaz, G., Rincón, A.F.D.: Elastodynamic analysis of a gear pump. part i: Pressure distribution and gear eccentricity. Mechanical Systems and Signal Processing 24(7), 2160-2179 (2010)

14. Ohlendorf, H.: Verlustleistung und erwärmung von stirnrädern (1958)

15. Pleguezuelos, M., Pedrero, J.I., Sánchez, M.B.: Analitycal model of the efficiency of spur gears: Study of the influence of the design parameters. In: Proceedings of the ASME Design Engineering Technical Conference, vol. 8, pp. $557-565$ (2011)

16. Sánchez, M.B., Pleguezuelos, M., Pedrero, J.I.: Toothroot stress calculation of high transverse contact ratio spur and helical gears. Meccanica 49(2), 347-364 (2014) 
17. Theodossiades, S., Natsiavas, S.: Geared rotordynamic systems on hydrodynamic bearings. In: Proceedings of the ASME Design Engineering Technical Conference, vol. 6 A, pp. 1099-1107 (2001)

18. Vedmar, L., Henriksson, B.: A general approach for determining dynamic forces in spur gears. Journal of Mechanical Design, Transactions of the ASME 120(4), 593-598 (1998)

19. Weber, C.: The Deformation of loaded gears and the effect on their load carrying capacity. Department of Scientific and Industrial Research, London (1951)

20. Xu, H.: Development of a generalized mechanical efficiency prediction methodology for gear pairs (2005)

21. Yada, T.: Review of gear efficiency equation and force treatment. JSME International Journal, Series C: Dynamics, Control, Robotics, Design and Manufacturing 40(1), 1-8 (1997) 